\title{
Charles Nodier, Le Voleur
}

\section{Stefano Lazzarin}

\section{(2) OpenEdition}

\section{Journals}

\section{Edizione digitale}

URL: http://journals.openedition.org/studifrancesi/33381

DOI: 10.4000/studifrancesi.33381

ISSN: 2421-5856

\section{Editore}

Rosenberg \& Sellier

\section{Edizione cartacea}

Data di pubblicazione: 1 décembre 2005

Paginazione: 658-659

ISSN: 0039-2944

\section{Notizia bibliografica digitale}

Stefano Lazzarin, «Charles Nodier, Le Voleur», Studi Francesi [Online], 147 (XLX | III) | 2005, online dal 30 novembre 2015, consultato il 18 avril 2021. URL: http://journals.openedition.org/studifrancesi/33381 ; DOI: https://doi.org/10.4000/studifrancesi.33381

\section{Questo documento è stato generato automaticamente il 18 avril 2021.}

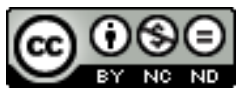

Studi Francesi è distribuita con Licenza Creative Commons Attribuzione - Non commerciale - Non opere derivate 4.0 Internazionale. 


\title{
Charles Nodier, Le Voleur
}

\author{
Stefano Lazzarin
}

\section{NOTIZIA}

CHARLES NODIER, Le Voleur, texte établi et présenté par LUDOVICA CIRRINCIONE D'AMELIO, Paris, Honoré Champion, «Textes de Littérature moderne et contemporaine», 2004, pp. 144

1 Dopo la Promenade de Dieppe aux montagnes d'Ecosse (cf. l'édition établie et commentée par G.Zaragoza, Paris, Honoré Champion, 2003), la collana dell'editore Champion dedicata ai «Textes de Littérature moderne et contemporaine» accoglie un altro testo di Nodier che finora era noto soltanto agli specialisti: il racconto lungo o romanzo breve Le Voleur. L'opera, la cui prima stesura risale al 1804, non era mai stata pubblicata in vita di Nodier, e neppure dopo la sua morte: il manoscritto era rimasto sepolto negli archivi dei discendenti dello scrittore, la famiglia Mennessier-Nodier, da cui ora lo trae la sollecitudine della curatrice. Ludovica Cirrincione d'Amelio è ben nota agli studiosi di Nodier per varie pubblicazioni precedenti, fra cui ricorderemo, in questa sede, il volume uscito in italiano una quindicina di anni fa: Il Prisma dell'illusione. Saggi su Nodier, Roma, Bulzoni, 1988; e un saggio comparso all'interno di una miscellanea, su un argomento che ha, come vedremo, qualcosa a che vedere con Le Voleur: «Su Jean Sbogar: Lothario e il suo doppio", in Aspetti del romanzo francese (studi in onore di M. Colesanti, Roma, Bulzoni, 1996, pp. 137-151). Del Voleur, Cirrincione d'Amelio fornisce un'edizione critica agile e leggibile, completandola con una descrizione del manoscritto e un regesto di varianti (pp. 121-132); ella firma anche un'introduzione (pp. 7-26) che colloca il racconto all'interno dell'opera di Nodier, ricostruendo in particolar modo i rapporti che esso intrattiene con le opere giovanili (Les Proscrits, Le Peintre de Saltzbourg, Essais d'un jeune barde), nonché con l'importante esperienza dell'adesione ai Méditateurs (un gruppo di pittori allievi di David, primitivisti e fautori di teorie pitagoriche, dei quali ancora non si conosce esattamente la dottrina, perché essa fu attentamente dissimulata ai profani da parte degli adepti). 
Oltreché di lettura godibilissima, Le Voleur è un testo affascinante per chi si interessa all'opera di Nodier; ne anticipa infatti quasi tutte le componenti principali: è una sorta di limbo da cui provengono le opere future dello scrittore, un archetipo che le contiene in nuce. L'ossessione nodieriana dell'Age d'or, ad esempio, è chiaramente enunciata in molte pagine che condannano la Società, «boîte de Pandore» (p. 55) da cui sono usciti tutti i mali e tutte le ingiustizie; e già nel Voleur compare l'idolo polemico principale degli anni Trenta, la grande illusione della Perfettibilità contro cui si scaglierà il dottor Néophobus ( $c f$. Nodier, Critiques de l'imprimerie par le docteur Néophobus, a cura di D. Barrière, Paris, Éditions des Cendres, 1989): quella «contagion de la perfectibilité» da cui solo alcuni popoli rimasti allo stato primitivo sono immuni, «système funeste dont l'arbre de la science du bien et du mal est une visible allégorie» (p. 76). Ancora: gli scenari gotici così frequenti in questo romanzo giovanile - $\mathrm{i}$ sotterranei in cui viene rinchiuso il protagonista Paul, il castello di Linberg che serve da riparo ai briganti di Lazare - annunciano le lugubri invenzioni di Mademoiselle de Marsan (1832); l'incubo delle teste tagliate e saltellanti, che si legge nel cap. VI (pp. 98-9), ritornerà in pagine famose di Smarra (1821) e della Fée aux Miettes (1832); i sogni di Paul (pp. 91-92), Maria (p. 103), e ancora Paul (pp. 117sq.) rivelano quell'interesse per la vita notturna, «cette vie fantastique dont se compose la moitié de la nôtre» (Nodier, De Quelques Phénomènes du sommeil [1831], a cura di E. Dazin, Bègles, Le Castor Astral, 1996, p. 23), che caratterizzerà il futuro teorico del sonno, del sogno e dell'incubo. E si potrebbe continuare a lungo in questo elenco di presagi dell'avvenire.

Ma soprattutto, Le Voleur è una prefigurazione nettissima, quasi il primo abbozzo, del romanzo più noto di Nodier, Jean Sbogar (1818): entrambi i testi, infatti, sono costruiti intorno al grande tema dei briganti che, da Schiller in giù, ebbe tanta fortuna nella letteratura occidentale. Sui rapporti che intercorrono fra Le Voleur e Jean Sbogar rimandiamo di nuovo all'introduzione di Cirrincione d'Amelio, che evidenzia analogie e differenze, spiegando in che senso, e fino a che punto, Le Voleur può essere considerato come un «avant-texte du roman de la maturité» (p. 8; e, su tutta la questione, si vedano le pp. 21-26, «Du Voleur à Jean Sbogar»). Qui ci limiteremo a menzionare ciò che principalmente separa i due romanzi, e rende conto degli anni trascorsi nel frattempo: vale a dire il pessimismo più radicale, il disincanto ormai irrimediabile che traspaiono dall'opera della maturità. «Si Le Voleur se clôt avec un rêve, celui de Paul, qui porte en lui un message positif car il annonce le salut, Jean Sbogar est vraiment le roman de l'échec, de l'impossible régénération. [...] L'utopie égalitaire, le rêve de primitivisme qui animait Lazare et qui anime Jean Sbogar sont destinés à disparaitre sous le despotisme. Lothario, qui en est le dernier interprète, ne peut subsister sans Jean Sbogar, et son rêve s'efface avec lui» (p. 26). 